\title{
Memory, amnesia, and frontal lobe dysfunction
}

\author{
DANIEL L. SCHACTER \\ University of Toronto, Toronto, Ontario, Canada
}

\begin{abstract}
Lesions restricted to the frontal lobes do not ordinarily produce an amnesic syndrome in man. However, recent research has demonstrated that amnesic patients who are characterized by signs of frontal lobe pathology show patterns of memory performance that are different from those shown by amnesic patients without frontal signs. This article reviews evidence concerning the influence of frontal lobe pathology on amnesic disorders, discusses different interpretations of this evidence, and draws on research from human and animal neuropsychology as well as cognitive psychology in an attempt to clarify the role of frontal damage in the amnesic syndrome.
\end{abstract}

Organic amnesia is typically associated with neural damage in either the diencephalic or medial temporal regions of the brain (e.g., Butters \& Cermak, 1980; Scoville \& Milner, 1957; Squire, 1982b, 1986; Weiskrantz, 1985; Whitty \& Zangwill, 1977). The cardinal feature of the amnesia produced by lesions of these structures is a severe impairment in the acquisition of many kinds of new information that contrasts with relatively intact intellectual function and normal or nearnormal immediate memory (Cermak, 1982; Hirst, 1982; Moscovitch, 1982; Piercy, 1977; Squire \& Cohen, 1984). Recent evidence, however, indicates that the memory function of amnesic patients can be influenced markedly by frontal lobe dysfunction (e.g., Moscovitch, 1982; Squire, 1982a). This observation represents a significant theoretical puzzle, because it has long been acknowledged that lesions restricted to the frontal lobe do not produce a full-blown amnesic syndrome (e.g., Milner, 1964, 1982; Stuss \& Benson, 1986). It has become increasingly clear that understanding of this puzzle may be crucial to the development of theoretical ideas concerning the nature of organic amnesia.

The present article examines evidence that links frontal lobe pathology with amnesic disorders, considers different interpretations of this evidence, and draws on relevant research from neuropsychology and cognitive psychology in an attempt to clarify the nature of frontal lobe influences on organic amnesia. The article begins with a review of data that demonstrate that amnesic patients with frontal pathology exhibit special deficits on tasks in which performance depends on memory for cer-

This article was supported by the Natural Sciences and Engineering Research Council of Canada (Grant U0361) and by a Special Research Program Grant from the Connaught Fund, University of Toronto. I am grateful to David Olton, Mary Lou Smith, Larry Squire, Endel Tulving, and Gordon Winocur for comments concerning earlier drafts of the article, and I thank Carol A. Macdonald for help with preparation of the manuscript and James Worling for running the experiment on recency judgments. Requests for reprints should be addressed to Daniel L. Schacter, at Department of Psychology, University of Toronto, Toronto, Ontario, Canada M5S 1A1 (before August 1, 1987) or at Department of Psychology, University of Arizona, Tucson, AZ 85721 (after August 1, 1987). tain kinds of spatial and temporal information, deficits that are not observed in amnesic patients without frontal signs. Next, relevant data from studies concerning the effects of restricted frontal lesions on memory functions in humans and other primates are considered. These studies have demonstrated selective deficits of memory for spatiotemporal information following restricted frontal lesions, thereby indicating that frontal regions play a specific role in certain memory functions. Additionally, data from normal subjects showing that memory for spatiotemporal information may be a relatively automatic process are discussed. These data support the idea that deficits in memory for spatiotemporal information associated with frontal lobe pathology do not necessarily reflect a generalized inability to engage in effortful or resource-demanding cognitive processing. It is concluded that (1) special memory deficits observed in amnesic patients with frontal lobe pathology are central to our theoretical understanding of organic amnesia, and (2) such deficits can provide important insights into the nature of normal memory that cannot be readily obtained from the study of "pure" amnesic patients.

\section{The Influence of Frontal Lobe Pathology on Amnesic Disorders}

This section describes links between amnesia and frontal lobe damage that have emerged in research concerning amnesic patients' performance on tasks that tap processing and remembering of certain kinds of spatial and temporal information. Studies of the relationship between patients' recall or recognition of recently presented items and their memory for the items' spatiotemporal contexts will be discussed first, followed by consideration of research on the phenomenon of proactive interference.

Memory for spatiotemporal context in amnesia. Investigators of memory disorders have long been concerned with the question of whether the fundamental deficit in amnesia involves the encoding and retrieval of contextual information (for reviews, see Mayes, Meudell, \& Pickering, 1985; Stern, 1981; Winocur, 1982). This issue is far from settled, not in the least because it is difficult to define precisely what is meant by such terms as con- 
textual information or spatiotemporal context. In the present paper, these terms refer to global information about when and where a specific event took place, such as the room in which a learning episode occurred, the temporal relationship of one episode to another episode, and so forth. The terms item memory and item information are used to refer to what occurred during a particular episode.

Clinical observations have indicated that amnesic patients have poor memory for the spatiotemporal contexts of recent episodes, even when they can recall some of the items imparted to them during the episodes (Claparède, 1911/1951; Luria, 1976; MacCurdy, 1928; Williams \& Zangwill, 1950; Zubin, 1948; see Schacter, in press, for review). Such observations, however, are not sufficient to establish that problems with spatiotemporal memory represent the fundamental deficit in amnesic patients. It is possible that poor contextual memory is a consequence-rather than a cause - of a generally "weak" or "degraded" memory (Mayes \& Meudell, 1981a, 1981b). To argue that amnesic patients have special problems remembering spatiotemporal context, it is important to demonstrate that amnesics have poor contextual memory relative to controls even when item recall and recognition performance of the two groups have been equated by appropriate experimental manipulations. Several recent studies have attempted to do so by testing controls at long delays after study and comparing their performance to that of amnesic patients who were tested at short delays. Issues pertaining to the role of frontal lobe pathology have arisen in these studies.

In an experiment reported by Squire (1982a), subjects studied sentences presented on two different lists separated by a short temporal interval, and were later tested for sentence recognition and temporal discrimination (i.e., whether a given sentence appeared on the first or second list). The recognition performance of control subjects at the long delay was equivalent to that of Korsakoff patients at the short delay. Nevertheless, Korsakoff patients' performance on the temporal discrimination task at the short delay was significantly impaired with respect to controls' performance at the long delay. Because recognition performance of the two groups was equivalent at the two delays, it is plausible to argue that Korsakoff patients exhibited a selective temporal memory impairment that cannot be entirely accounted for by their "weak" or "degraded" recognition performance. By contrast, the temporal discrimination performance of patients rendered amnesic by bilateral electroconvulsive therapy (ECT) and patient N.A., whose amnesia was caused by a lesion in the dorsomedial nucleus of the thalamus, was no worse than controls' performance when recognition memory of the two groups was equated. Squire suggested that the Korsakoff patients' disproportionately poor memory for temporal information might be related to the frontal lobe dysfunction that is known to occur in conjunction with long-term alcohol abuse. Squire found that his Korsakoff patients performed worse on tasks that were sensitive to frontal lobe pathology, such as the Wisconsin Card Sorting Test (Milner, 1963) and the Benton Word Fluency Test (Benton, 1968), than did either N.A. or the ECT patients. Moreover, within the Korsakoff group, he found a strong positive correlation between performance on the frontal-sensitive tasks and performance on the temporal discrimination task, whereas there was no correlation between performance on the frontal tasks and level of sentence recognition.

A relationship between disproportionately poor contextual memory and frontal lobe pathology was also observed in an experiment by Schacter, Harbluk, and McLachlan (1984) concerning the phenomenon of source amnesia: retrieval of experimentally presented information without recollection of the spatiotemporal context in which it was acquired (cf. Evans \& Thorn, 1966). In this study, amnesics and controls were told fictional characteristics about well-known and unknown people (e.g., "Bob Hope refuses to eat chicken') by one of two experimental sources, and were later tested for retention of item and sources. Level of item recall in the two groups was equated by testing amnesics after brief delays of seconds and minutes and testing controls after a 1-week delay. It was found that the amnesic patients exhibited more source amnesia than did controls when level of item recall was held constant: On nearly $40 \%$ of the trials on which they retrieved the correct answer, amnesics failed to recollect that either of the sources had imparted it to them, whereas normals tested at the 1-week delay rarely failed to remember that a recalled item derived from one of the experimental sources. The amnesics in this study were characterized by diverse etiologies (early stages of Alzheimer's disease, anoxia, ruptured anterior communicating artery aneurysm, and closed-head injury), but most of them performed quite poorly on tasks sensitive to frontal lobe pathology (the Wisconsin Card Sorting Test and the Benton Word Fluency Test). When amnesics' performance on these tasks was related to how frequently they forgot when and where a recalled item was acquired, a strong positive correlation was observed. However, there was a nonsignificant relationship between performance on the frontal-sensitive tasks and level of item recall.

Taken together, the data reported by Squire (1982a) and by Schacter et al. (1984) suggest that impairments of spatiotemporal memory that are disproportionately severe relative to impairments of item recall and recognition are associated with signs of frontal lobe dysfunction. The fact that level of item recall or recognition was unrelated to performance on the frontal-sensitive tasks in both studies suggests that this association is not simply a reflection of overall level of impairment: If patients with signs of frontal lobe damage were generally more impaired than nonfrontal patients, one would have expected them to perform more poorly on item recall and recognition tasks.

It is important to emphasize that the notion of disproportionately poor spatiotemporal memory is a relative one that has meaning only with respect to a particular level of item recall or recognition. For example, a patient such 
as the well-known amnesic H.M., who performs quite well on frontal-sensitive tasks, would no doubt perform quite poorly on tasks that tapped memory for spatiotemporal context. However, the results of Squire (1982a) and Schacter et al. (1984) suggest that if H.M.'s level of item recall or recognition could be brought to the level of controls' (e.g., by long presentation time and testing at a brief delay), his memory for spatiotemporal context would also approximate that of controls. These ideas imply that further instances of disproportionately poor memory for spatiotemporal context will be observed in amnesics in whom there are grounds for suspecting frontal lobe damage, such as Korsakoff patients, Alzheimer patients, or patients with ruptures of the anterior communicating artery. Although there is as yet little relevant evidence, several studies are consistent with this suggestion. Huppert and Piercy (1976) found that Korsakoff patients recognized pictures that had been presented on one of 2 days as efficiently as controls did. The Korsakoff patients, however, were severely impaired at discriminating between the temporal contexts in which the pictures occurred: They performed poorly when required to state on which of the 2 days they had seen a presented picture. In a related study, Huppert and Piercy (1978) presented pictures to normals and controls either once or three times on 2 separate days, and asked them to make recency judgments concerning whether a picture had been presented "today" or "yesterday." Korsakoff patients responded "today" equally often to pictures that had been presented three times the previous day (36\%) and once on the day of the test (36\%), whereas control subjects responded "today" much less often to pictures presented three times the previous day (9\%) than to pictures presented once on the day of the test $(68 \%)$. These data indicate that Korsakoff patients retained little temporal information concerning when the pictures had been presented, and perhaps based their judgments of recency and frequency on the general "strength" of a memory trace. The temporal judgments of control subjects, by contrast, were much more sensitive to specific information concerning recency and frequency of occurrence. Note, however, that Huppert and Piercy did not report data concerning item recognition. Since it is likely that their recognition memory was impaired, Korsakoff patients' impaired temporal judgments could be attributable to generally degraded memory. If so, such an impairment should be observed in normal subjects tested at appropriately long delays. Meudell, Mayes, Ostergaard, and Pickering (1985) examined this idea, and found that the recency judgments of normals tested at a long delay distinguished between time of occurrence more accurately than did those of Korsakoff amnesics, thereby supporting the notion of a disproportionate impairment of memory for temporal information in Korsakoff patients.

Research reported by Winocur and Kinsbourne (1978) suggests that Korsakoff patients also have problems using features of spatial context to aid memory performance. They found that Korsakoff patients' acquisition of paired associates improved significantly, relative to controls, when learning and testing were carried out in a highly distinctive environmental context (consisting of colored lights and classical music) versus when they were done in an ordinary context. This finding suggests that Korsakoff patients have special difficulties in responding to environmental cues, difficulties than can be overcome when the patients are placed in a distinctive and unusual environmental context. Mayes, Meudell, and Som (1981) compared paired-associate performance of normal subjects in unusual and in ordinary contexts when testing was carried out after a long delay. Normal subjects performed no better in the unusual context than they did in the ordinary context, suggesting that Winocur and Kinsbourne's data cannot be accounted for in terms of generally weak or degraded memory on the part of amnesic patients.

The foregoing studies support the view that the difficulties amnesic patients who are characterized by signs of frontal lobe pathology have in processing and remembering contextual information are not entirely accounted for by their deficits in item recall and recognition. Is there any evidence that such disproportionately poor contextual memory occurs in patients without signs of frontal lobe pathology? The only study to report such evidence is one by Hirst and Volpe (1982), which included a variety of amnesic patients who, the authors stated, performed relatively well on frontal-sensitive tasks. These patients demonstrated little, if any, impairment on recognition tests, but performed more poorly than controls when required to make temporal order judgments concerning recently presented words or past public events. Several points about this study should be noted. On the wordmemory task, the overall pattern of results for recognition and temporal order judgments were quite similar: Normal subjects' performance was higher in both cases. The recognition differences, however, failed to achieve statistical significance. This finding may have resulted from the presence of ceiling effects, and the relatively small number of observations in individual experimental conditions. The observation of significant differences between amnesics and controls for temporal order judgments is clouded by the puzzling finding that amnesics' performance was well below the chance level in several of the conditions that yielded differences. On the public events task, recognition memory performance approached ceiling for both amnesics and controls, suggesting the possibility that a recognition impairment on the part of amnesics would have emerged in a more difficult task, as would be expected on the basis of a large number of studies (for similar concerns, see Mayes et al., 1985). In short, the Hirst and Volpe data do not demonstrate unequivocally that amnesics who perform well on frontalsensitive tasks exhibit disproportionately poor memory for temporal context.

Proactive interference effects. Proactive interference (PI) refers to the deleterious effect that a particular learning experience can have on subsequent learning. Research with normal subjects suggests that sensitivity to proactive interference is closely linked with temporal discrimination and memory processes (e.g., Underwood, 1977). 
It has been shown that, under certain conditions, amnesic patients are more sensitive to the buildup of PI than are control subjects (e.g., Kinsbourne \& Winocur, 1980; Winocur \& Weiskrantz, 1976). In these studies, subjects studied successive paired-associate lists in which the same stimulus term was paired with different response terms. Amnesic patients showed an exaggerated tendency to intrude the first-list responses onto successive lists. This hypersensitivity to PI has been interpreted as a consequence of an impaired spatiotemporal memory that prevents amnesic patients from remembering the list membership of response terms. Since many of the patients who show this phenomenon are Korsakoff patients, it is possible that frontal lobe dysfunction plays some role in it. However, Warrington and Weiskrantz's $(1974,1978)$ experiments, which also provide evidence that amnesic patients are extremely sensitive to interference, included a variety of patients, not all of whom would be expected to have frontal lobe problems. Accordingly, we cannot be entirely certain that sensitivity to PI depends crucially on frontal lobe pathology.

Schacter, Moscovitch, Tulving, McLachlan, and Freedman (1986) have recently reported a related interference phenomenon that may also depend on frontal lobe involvement in amnesia. Schacter et al. required amnesic patients to remember the locations of objects hidden at successive locations. It was found that patients, after a brief delay, successfully retrieved objects hidden at an initial location. However, they subsequently failed to retrieve objects at new locations, and instead searched for them at the old, initial location. Two kinds of evidence suggest that this phenomenon of mnemonic precedence (Schacter et al., 1986) depends in some way on the presence of frontal lobe pathology. First, Schacter et al. noted that all of their amnesic patients showed signs of frontal lobe pathology. Second, Diamond and Goldman-Rakic (1983) have observed a phenomenon similar to mnemonic precedence in monkeys with frontal lobe lesions (also see Diamond, 1985).

Studies of the phenomenon of release from PI also suggest a role for frontal lobe pathology in amnesia. This phenomenon was studied extensively in normal subjects by Wickens (1970), who developed a paradigm in which subjects are presented with and tested on four successive lists containing words from a particular category, and then given a list containing words from a different category. In normal subjects, recall performance decreases over the first four trials, reflecting the buildup of PI, but improves on the fifth trial; the improved performance is referred to as release from PI. Using similar paradigms, studies of Korsakoff amnesics have demonstrated that patients show considerable buildup of PI over the first four trials, but fail to improve performance when the category is shifted on the release trial (Cermak, Butters, \& Moreines, 1974; Kinsbourne \& Wood, 1975). Zatorre and McEntee (1983) reported similar observations in a severely amnesic head-injured patient with a large lesion to the left frontal lobe. However, Winocur, Kinsbourne, and Moscovitch
(1981) have shown that Korsakoff patients do show release to a categorical shift if the stimuli on the release trial are rendered highly distinctive by changes in the colors of target words and the background on which they are printed. Thus, the Korsakoff patients' deficit may be attributable to an inability to process salient contextual features, although the type of contextual information assessed in the Winocur et al. experiment differs from that of the contextual information discussed earlier. By contrast, amnesic patients who are free of frontal lobe problems demonstrate normal release on the Wickens test (Cermak, 1976; Moscovitch, 1982), whereas frontal-lobe patients, like Korsakoff patients, do not release normally (Moscovitch, 1982), although failure to show normal release from PI may be observed only in those frontal patients who also exhibit some memory deficits (Freedman \& Cermak, 1986). Thus, failure to demonstrate release from PI can be linked both to frontal problems and to difficulties in the processing of some contextual features.

\section{Interpretation of Frontal Lobe Influences on Memory Disorders}

The foregoing studies indicate clearly that, on tasks that require access to various types of spatiotemporal information, the performance of amnesic patients who are characterized by signs of frontal lobe pathology is different from that of patients without frontal signs. What are the implications of this observation for theories of the amnesic syndrome? At least two broad alternatives can be distinguished. One possibility is that amnesic patients with frontal lobe deficits have a specific and primary memory dysfunction within the domain of spatiotemporal information that is not observed in other amnesic patients. If this is the case, the deficits observed in such patients could have important implications for theories of amnesia, because the role of spatiotemporal memory deficits in the amnesic syndrome is central to various theoretical positions (e.g., Butters \& Miliotis, 1985; Mayes \& Meudell, 1983; Mayes et al., 1985; Schacter \& Tulving, 1982a, 1982b; Squire, 1987; Squire \& Cohen, 1984; Winocur, 1982).

A second possibility, however, must be considered before the first possibility can be accepted. It is possible that the special spatiotemporal memory deficits observed in amnesic patients with frontal signs represent nonspecific impairments that are secondary to other problems associated with frontal lobe dysfunction, problems that are not concerned specifically with memory function. Since amnesia can occur in the absence of frontal lobe dysfunction, and restricted frontal lobe lesions typically do not produce an amnesic syndrome, the possibility that frontalrelated memory deficits in amnesic patients are secondary to other, rather general cognitive problems must be considered carefully. For example, if amnesic patients with frontal lobe deficits are characterized by sensoriperceptual impairments that prevent them from registering experimental input accurately, are so grossly disoriented or 
demented that they cannot properly comprehend the nature of a task, suffer from language or motor problems that prevent them from expressing retained knowledge, or are not sufficiently motivated or aroused to perform a task, then it would be appropriate to regard any special memory problems associated with these impairments as nonspecific deficits that need not command our theoretical attention. If, however, deficits in these areas can be excluded, then it may make good theoretical sense to examine closely the nature of memory impairments that are produced by frontal deficits.

On the basis of the literature discussed thus far, there is no reason to believe that the special spatiotemporal memory deficits exhibited by amnesics with signs of frontal lobe pathology can be attributed to perceptual impairments, gross dementia, or motor/language difficulties. Patients in the relevant studies were all characterized by relatively normal performance on perceptual, intellectual, linguistic, and motor tasks. There is, however, some basis for suspecting a role of motivation/arousal deficits: Korsakoff patients, who participated in most of the relevant studies, are known to suffer from problems of low motivation and arousal (e.g., Butters \& Cermak, 1980; Oscar-Berman, 1980), and it is widely recognized that patients with restricted frontal lesions are often unmotivated and lack the initiative and resources that are necessary to perform complex tasks (e.g., Damasio, 1979; Eslinger \& Damasio, 1985; Stuss \& Benson, 1986). To link such deficits with findings of disproportionately poor spatiotemporal memory, one could argue that tasks that tap memory for spatiotemporal context are more resourcedemanding than are tests of item recognition, and that, hence, generally underaroused and unmotivated subjects perform more poorly on them. To the extent that this argument is valid, one could conclude that amnesic deficits associated with frontal lobe dysfunction are not telling us anything specific about memory for spatiotemporal information. Instead, they may indicate that unmotivated or underaroused subjects perform disproportionately poorly on resource-demanding tasks.

There are at least two ways in which the proposal that disproportionate spatiotemporal deficits associated with frontal lobe dysfunction are nonspecific consequences of motivation and arousal deficits could be countered. The first would be to provide evidence that the processing and retention of spatiotemporal information was specifically associated with the frontal regions. If such specificity could be demonstrated, it would be difficult to maintain that poor spatiotemporal memory in amnesics with frontal lobe pathology resulted from a generalized cognitive sluggishness. The second of these two ways would be to demonstrate that memory for spatiotemporal context did not require a large amount of effort and motivation, but was, instead, a relatively automatic function that required little investment of cognitive energy. If memory for spatiotemporal context was a relatively automatic function, then any generalized motivational or arousal deficits associated with frontal lobe dysfunction would not likely play a major role in spatiotemporal memory deficits. Thus, if the evidence indicated that frontal regions were specifically associated with memory for spatial and temporal context, and that spatiotemporal information could be encoded in a relatively automatic manner, there would be grounds for rejecting the idea that memory deficits associated with frontal lobe dysfunction in amnesic patients were attributable to nonspecific cognitive and motivational impairments. In the following sections of the paper, I will examine evidence concerning the effects of frontal lobe lesions on memory function in man and in nonhuman primates that bears upon the specificity of spatiotemporal deficits; I will then discuss studies of memory for spatiotemporal context in normal human subjects that address the question of whether spatiotemporal information is processed automatically.

\section{Memory Function and Frontal Lobe Lesions in Man}

As noted earlier, it has been frequently observed that patients with relatively restricted frontal lobe lesions do not develop a full-blown amnesic syndrome (e.g., Mayes \& Meudell, 1983; Milner, 1964; Moscovitch, 1982; Squire, 1982a; Stuss \& Benson, 1986). Because "pure" frontal lobe patients are not amnesic, it may be questionable whether the frontal lobes should be assigned any role at all in mnemonic functions. A number of studies have provided evidence in support of this contention. Teuber and Weinstein (1954) examined free recall of items from a formboard in patients with frontal lesions or posterior lesions produced by missile wounds. Free-recall performance was higher for the frontal patients than for the patients with posterior damage. Ghent, Mishkin, and Teuber (1962) compared the performance of patients with unilateral left, unilateral right, and bilateral frontal damage with that of nonfrontal brain-injured patients and controls on tests of visual memory, tactual memory, digit span, and nonverbal object span. Memory was tested at a relatively brief delay $(15 \mathrm{sec})$. In all cases, the frontal patients performed as well as the nonfrontals and controls, and there was no evidence of differential impairment among the three frontal subgroups. Milner (1967) examined the performance of patients with unilateral left frontal damage on their delayed recall of paired associates and stories that had been presented in the visual and auditory modalities. Memory performance of the frontal patients was normal in all conditions. More recently, Jetter, Poser, Freeman, and Markowitsch (1986) reported that patients with unilateral and bilateral frontal lesions performed normally on free-recall, cued-recall, and recognition tests administered $15 \mathrm{~min}$ after presentation of a 16-item word list. On a 24-h delayed test, cued-recall and recognition performance remained normal, but free-recall performance was significantly impaired. Although the latter finding suggests that, under certain conditions, frontal lobe lesions may result in mild item recall deficits, most of Jetter et al.'s patients suffered from traumatic brain injury, thereby raising the possibility that they had incurred 
damage in extrafrontal regions that was not evident in the CT scan. Similarly, Freedman and Cermak (1986) described the cases of several frontal patients who appeared to have some difficulty with item recall. However, Freedman and Cermak could not rule out the possibility that these patients' memory problems were attributable to damage in areas outside the frontal lobe, such as the basal forebrain (see Damasio, Graff-Radford, Eslinger, Damasio, \& Kassell, 1985).

Although one must always be wary about accepting the null hypothesis, the results of the foregoing studies certainly do not encourage the view that restricted frontal lobe lesions are sufficient to produce memory disorders of the kind that are encountered in the classical amnesic syndromes. Remember, however, that the data considered in the previous section of the article indicated that signs of frontal lobe pathology were unrelated to level of recall and recognition performance; they were correlated with performance on tasks that involve memory for spatiotemporal information. The studies reviewed in the foregoing paragraph were all concerned with recall and recognition performance; the tasks used in these experiments did not require memory for spatiotemporal information.

Several investigators, however, have provided data concerning memory for spatiotemporal information in frontal patients (for discussion, see Milner, Petrides, \& Smith, 1985; Squire, 1987; Stuss \& Benson, 1986). These studies indicate that when frontal patients are given tasks that require memory for temporal order or demand temporal discriminations, substantial impairments can be detected. Perhaps the most elegant demonstration of a selective deficit of temporal memory in frontal lobe patients is found in a study by Corsi (cited by Milner, 1971, 1974). In one task, Corsi presented patients with lists of common words and tested memory in two different ways. On a two-choice recognition task, patients indicated which of the two words (one old, one new) had appeared earlier in the list; on a two-choice recency-judgment task, they indicated which of two old words had appeared more recently in the list. Corsi found that patients with unilateral left and right frontal damage performed normally on the recognition task. But the patients with left-sided frontal damage were impaired on the recency-judgment task. By contrast, patients with unilateral left temporal damage were impaired on the recognition task but not on the recency task. Corsi observed a similar double dissociation among patients with right-sided damage when nonverbal materials were used: Patients with right-sided frontal damage were impaired on the recency task but not on the recognition task, whereas patients with right-sided temporal damage were impaired on the recognition task but not on the recency task.

The results of several other studies indicate that the deficits of temporal memory in frontal patients demonstrated by Corsi have a good deal of generality. Lewinsohn, Zieler, Libet, Eyeberg, and Nielson (1972) found that unilateral left, unilateral right, and bilateral frontal patients were substantially impaired when required to recall the temporal order of recently presented pictures and words. By contrast, the frontal patients were much less impaired on memory tasks that did not demand ordered recall. Milner and Kolb (1985) found that patients with unilateral frontal damage were impaired when required to reproduce, in correct temporal order, a series of arm and facial movements. Smith and Milner (1983) found that patients with either left- or right-sided frontal lesions were impaired on tasks requiring estimates of frequency of occurrence of experimental stimuli, which require memory for temporal information.

In addition to their problems with remembering temporal order, patients with frontal damage also perform poorly when memory tasks require various types of sequential organization (della Rocchetta, 1986; Petrides \& Milner, 1982), recollection of autobiographical episodes with specific temporal dates (Baddeley \& Wilson, 1986), or accurate temporal discriminations (Prisko, cited in Milner, 1964). In Prisko's study, the performance of unilateral left and right frontal patients was compared with that of unilateral left and right temporal patients, using delayed comparison tasks in which the subjects indicated whether a test stimulus was identical to or different from a target stimulus that had been presented $60 \mathrm{sec}$ earlier. When each study-test trial was composed of unique materials that did not recur on subsequent trials (nonsense figures), performance of both groups of frontal patients was unimpaired. Prisko also examined memory performance on tasks in which some of the stimuli (flashes, clicks, and colors) recurred from trial to trial. Under these conditions, subjects had to remember whether they had seen the test stimulus on the current trial or on a previous trial to make a correct response. Thus, the tasks with recurring stimuli demanded memory for temporal context, whereas the task with nonrecurring stimuli did not. Paired-comparison performance of both groups of frontal patients was impaired, with respect to that of temporal patients and controls, when stimuli recurred from trial to trial.

Chorover and Cole (1966) compared the performance of unilateral and bilateral frontal patients with that of nonfrontal patients and controls on a delayed alternation task that required subjects to make a response opposite to the one made on an immediately preceding trial. Temporal discrimination plays an important role in this task: Subjects must remember their response from the immediately preceding trial and discriminate it from responses made in earlier trials in order to make a correct alternation response. Chorover and Cole's results were characterized by a good deal of variability within and among subject groups, and hence are not entirely clear-cut. There was, however, evidence of impairment in the frontal groups: $53 \%$ of frontal patients failed to achieve criterion, whereas only $33 \%$ of patients with nonfrontal lesions failed to do so. All of the controls achieved criterion. Using a similar approach, Pribram, Ahumada, Hartog, and Roos 
(1964) found that patients who had undergone bilateral frontal lobotomies were impaired on a variety of alternation tasks that demanded temporal discriminations.

In a recent study, Stuss et al. (1982) found that schizophrenics who had undergone bilateral prefrontal leucotomy were not impaired on a number of standard memory tasks, including the Wechsler Memory Scale and tests of verbal and nonverbal recall and recognition. The frontal patients, did, however, exhibit excessive sensitivity to proactive interference on the Brown-Peterson trigram recall task, in which subjects must make accurate temporal discriminations to determine whether a response is appropriate for a particular trial. Sensitivity to proactive interference in frontal patients has also been reported by Luria (1971).

The foregoing studies provide converging evidence for the view, proposed by various investigators (e.g., Diamond \& Goldman-Rakic, 1983; Fuster, 1980; GoldmanRakic, 1984; Milner, 1971; Milner et al., 1985; Stuss et al., 1982), that patients with relatively restricted frontal damage are impaired on memory tasks that require utilization of temporal information, and perform relatively normally on memory tasks that do not make temporal demands (for a demonstration of impaired learning by frontal patients in a nontemporal task, see Petrides, 1985). Less attention has been paid to frontal patients' memory for spatial context. Smith and Milner (1983) recently found that patients with unilateral frontal lesions were unimpaired on a task that required them to recall the spatial positions of objects previously presented in an array. However, it is not clear how the kind of information tapped by the Smith and Milner task, which concerns local features of spatial position, is related to the impairment of more global contextual information about the occurrence of an episode that is found in amnesic patients with frontal pathology.

The major issue that needs to be addressed with respect to the foregoing findings concerns the specificity of the temporal memory deficits: Are the frontal regions involved specifically in the processing and retention of temporal information, or are the selective deficits by-products of other functions in which the frontal areas are involved? The long and contentious history of research and theorizing concerning the nature of frontal lobe function (Teuber, 1964) provides ample warning that unequivocal answers to such a question will be difficult to obtain. In view of the spectrum of deficits that have been exhibited by frontal lobe patients, the multiplicity of functions that have been attributed to the frontal regions (Damasio, 1979; Fuster, 1980; Ingvar, 1983, 1985; Kolb, 1984; Luria, 1969; Stuss \& Benson, 1984, 1986), and the widespread neuroanatomical connections of the frontal areas to cortical and subcortical structures (Goldman-Rakic, 1984; Nauta, 1971, 1973), any attempt to postulate a single function that is uniquely "frontal" is no doubt an oversimplification and surely incorrect.

The complexity of the problem, however, need not prevent us from examining the possibility that specific fron- tal functions can be isolated and distinguished from one another. With respect to the present concerns, the major interpretive problem regarding the specificity of frontalrelated temporal memory impairments concerns the numerous other deficits that have been observed in frontal patients, including problems of planning (Milner, 1982; Shallice, 1982), regulation of verbal behavior (Luria, 1969), perseveration (Hécean \& Albert, 1975; Sandson \& Albert, 1984), verbal and nonverbal fluency (Benton, 1968; Jones-Gotman \& Milner, 1977), hypothesis testing (Milner, 1963), arousal (Luria, 1973), motivation (Eslinger \& Damasio,1985), and affect (Damasio \& Van Hoesen, 1983). Does the presence of such deficits imply that temporal memory problems are secondary to them, or at the very least inextricably intertwined with them? Although this question cannot be answered unequivocally, there is growing evidence that specific functional deficits are associated with different loci of damage within the frontal areas (Damasio, 1979; Drewe, 1974, 1975; Kolb \& Whishaw, 1985; Walsh, 1978). For example, deficits of arousal and emotion are typically associated with orbital-frontal damage, whereas cognitive deficits are more often found in association with dorsolateral frontal damage (e.g., Damasio \& Van Hoesen, 1983; Milner, 1964; Stuss \& Benson, 1986). In a summary of much of the relevant literature, Damasio (1979) argued that the numerous manifestations of frontal lobe pathology "need not be present at the same time or to the same degree" (p. 360), and concluded that the varied connections of the frontal regions to other brain regions "underscores the absurdity of the notion of a single frontal-lobe syndrome" (p. 371).

The notion that different manifestations of frontal lobe damage may be both functionally and neuroanatomically dissociable is important because it helps us to understand that even though temporal memory deficits may occur in conjunction with other impairments, they need not be dependent on them or related to them in a causal manner. The fact that multiple deficits often occur in frontal lobe patients may simply reflect the fact that, in clinical studies, it is difficult to control precisely the site and extent of brain damage. It is possible that when lesions are confined to specified locations, temporal memory deficits can be dissociated from other impairments. The extensive literature on frontal damage in nonhuman primates suggests that this is indeed the case.

\section{Memory for Spatiotemporal Information in Frontal Animals}

The question of whether frontal lesions yield memory deficits in nonhuman primates has an extended history that has been reviewed elsewhere (Fuster, 1980; Iversen, 1983). Three general types of tasks have been used to evaluate mnemonic function in most of this research. On delayed response tasks, bait is placed under one of two identical hiding wells in different spatial locations, and the animal is permitted to look for it after a delay of several seconds; the location of the bait varies from trial 
to trial. The delayed response task thus requires memory for spatial location. In addition, the task requires accurate temporal discrimination: The animal must be able to remember the location of the reward on the most recent trial in order to make the correct response. On delayed alternation tasks, the bait is placed under identical objects at different locations (spatial alternation) or under different objects at the same location (object alternation), and the animal is rewarded for making a response on Trial $n$ that is opposite to the one made on Trial $n-1$. As in delayed response, the location of reward varies randomly between the two places from trial to trial. A third task that has been used in relevant research is delayed matching-to-sample. Here, the animal is typically shown one of two colors (e.g., red or green). When both colors are subsequently displayed after a brief delay, the animal is rewarded for touching the one that matches the sample. Delayed matching-to-sample does not require memory for spatial location; the correct color may appear in the same or in a different location as the sample. It does, however, require the animal to discriminate among temporal contexts, because the same colors are used on successive trials.

Early research employing these tasks demonstrated that monkeys with extensive bilateral frontal lesions perform poorly on delayed response tasks and on both spatial and object alternation tasks (e.g., Jacobsen, 1935; Malmo, 1942; Mishkin \& Pribram, 1955, 1956). A major focus of subsequent research has concerned the question of whether different aspects of delayed response and delayed alternation deficits are related to damage in particular areas of the prefrontal cortex. There is now a good deal of evidence to suggest that this is the case. More specifically, a number of studies indicate that damage to certain areas within the dorsolateral frontal cortex underlie spatial memory deficits, whereas damage to the ventrolateral frontal cortex is implicated in various other mnemonic deficits displayed by frontal monkeys (e.g., Goldman \& Rosvold, 1970; Mishkin \& Manning, 1978; Mishkin, Vest, Waxler, \& Rosvold, 1969; Oscar-Berman, 1975; Passingham, 1975, 1985). It is known, for instance, that lesions of the dorsolateral frontal cortex produce delayed response deficits that increase in severity as a function of delay (Miller \& Orbach, 1972; Treichler, Hamilton, \& Halay, 1971); dorsolateral lesions do not impair performance on tasks that involve spatial processing but do not require retention of experimentally acquired information (Goldman \& Rosvold, 1970; Oscar-Berman, 1975). Electrical stimulation of the dorsolateral frontal region produces delayed response deficits when applied during the early stages of an 8-sec retention interval, but does not disrupt performance if applied during an intertrial period or during the early phases of cue presentation (Stamm, 1969). A particularly important finding is that delayed response and delayed spatial alternation deficits depend upon damage to specific areas within the principal sulcus of the dorsolateral frontal cortex: If lesions are confined to regions within the principal sulcus, impaired per- formance on spatial memory tasks is observed, but if lesions are made in the dorsolateral cortex outside the principal sulcus, such as in the arcuate sulcus, there is no impairment on spatial memory tasks (Butters et al., 1972; Goldman \& Rosvold, 1970; Goldman et al., 1971; Stamm \& Rosen, 1973).

There is some uncertainty concerning the role played by the dorsolateral frontal cortex in memory tasks that do not entail a spatial component, such as delayed matching-to-sample. The results of several studies indicate that when dorsolateral function is interfered with by lesions (Glick, Goldfarb, \& Jarvik, 1969), electrical stimulation (Kovner \& Stamm, 1972), or cooling (Bauer \& Fuster, 1976, 1978; Fuster \& Bauer, 1974), performance on delayed matching-to-sample is severely impaired, whereas performance on simultaneous matching is unimpaired. However, when dorsolateral lesions are confined to the principal sulcus, performance on nonspatial memory tasks, such as object alternation and delayed matching, are relatively unimpaired (Mishkin \& Manning, 1978; Mishkin et al., 1969; Passingham, 1975), suggesting the possibility that neural disruption in the aforementioned delayed matching-to-sample studies extended beyond the principal sulcus. Damage to the inferior-ventral regions of the frontal cortex does, however, impair performance on nonspatial memory tasks (Mishkin \& Manning, 1978; Mishkin et al., 1969; Passingham, 1975; see also Oscar-Berman, 1975).

It is worth noting that much of the debate in the literature has focused on the question of whether frontal involvement in mnemonic function is confined to situations that demand spatial memory. Several researchers have suggested that deficits on nonspatial memory tasks produced by lesions outside the principal sulcus are related to perseverative tendencies and difficulties with response inhibition (e.g., Mishkin, 1964; Mishkin \& Manning, 1978; Oscar-Berman, 1975). The debate over the role of spatial and nonspatial factors, however, has tended to obscure the fact that such tasks as delayed response, delayed alternation, and delayed matching-to-sample all contain a significant temporal component: Because the same stimuli recur from trial to trial, the animal must be able to distinguish the appropriate response on the current trial from responses made to the same stimuli on previous trials. The fact that accurate temporal memory is required on the tasks in which frontal animals are typically impaired raises a key question: Would animals with frontal damage perform poorly on memory tasks-spatial or otherwisethat do not have a significant temporal component? There is little relevant evidence. A task that could help to decide the issue is the trial-unique delayed matching-tosample procedure. In this task, a new set of stimuli (i.e., objects) is used on each trial, so that the animal is merely required to recognize the correct object on a particular trial and is not required to make temporal discriminations. In an early study, Meyer, Harlow, and Settlage (1951) found that monkeys with bilateral frontal lesions performed better in the trial-unique situation than in the stan- 
dard task with recurring stimuli, but that the performance of monkeys with unilateral lesions or no lesions did not differ in the two tasks. More recently, Mishkin and Bachevalier (1983) found that monkeys with dorsolateral lesions are not significantly impaired on the trial-unique procedure, although monkeys with lesions to the ventromedial frontal area are impaired on the trial-unique procedure.

Although much work needs to be done, there seems to be broad agreement between the results of animal and human studies: Lesions in the dorsolateral frontal regions impair performance on memory tasks that require temporal memory but apparently do not do so on ones that require nontemporal memory (i.e., item recall and recognition in man and trial-unique delayed matching-to-sample in monkey). The animal literature suggests that principal sulcus lesions may produce an even greater deficit on temporal tasks that also require memory for spatial information, but there is, as yet, no evidence from human frontal patients that demonstrates that spatial memory tasks yield greater impairments than do nonspatial ones.

The animal literature also indicates that impairments of spatiotemporal memory are dissociable from other consequences of frontal lobe dysfunction, such as perseveration (Mishkin, 1964; Mishkin \& Manning, 1978). This finding encourages the view that poor temporal-memory performance in frontal patients may not be dependent upon the perseverative tendencies that are frequently observed with frontal lobe pathology (Damasio, 1979; Milner, 1963). Although this issue is far from settled, it may be useful to entertain the possibility that some forms of perseveration are consequences-not causes-of poor temporal memory. For example, the finding that frontal patients make many prior-list intrusions on the Brown-Peterson task (Stuss et al., 1982) and also exhibit sensitivity to proactive interference in other situations (Luria, 1971, 1976) may be indicative of their inability to make accurate temporal discriminations. It is also possible that some of frontal patients' well-known perseverative tendencies on the Wisconsin Card Sorting Test (Milner, 1963) are attributable to an impaired ability to distinguish among the temporal contexts in which a particular response is appropriate.

In summary, the literature concerning nonhuman primates indicates strongly that the dorsolateral regions of the prefrontal cortex are related specifically to memory for spatiotemporal information (see Fuster, 1980, 1985, and Iversen, 1983, for more detailed expositions of this view). Interpretive caution must be exercised, of course, in any attempt to relate these findings to studies of human frontal and amnesic patients.

\section{Memory for Spatiotemporal Information in Normal Human Subjects: \\ An Automatic Process?}

As discussed earlier, it is important to consider the idea that poor memory for spatiotemporal information associated with frontal lobe pathology is a consequence of impaired strategic processing or of more generalized cognitive inertia. If memory for spatiotemporal information can be accomplished automatically, without the intervention of effortful processing, there would be grounds for rejecting this idea. This section considers pertinent evidence.

A growing number of recent studies have attempted to elucidate the differences between automatic and effortful processes. Automatic processes are those that occur without intention, require minimal processing capacity, do not interfere with other cognitive operations, are not sensitive to strategic influences and instructional manipulations, and do not improve with practice (Hasher \& Zacks, 1979; Zacks, Hasher, \& Sanft, 1982). By contrast, effortful processes are initiated intentionally, require significant processing capacity, interfere with other cognitive operations, are sensitive to strategic and instructional influences, and improve with practice (Hasher \& Zacks, 1979).

Converging evidence suggests that encoding of both temporal and spatial information may be achieved automatically. Perhaps the best-documented example of an automatic process is the encoding and retrieval of information concerning frequency of occurrence. Several studies have demonstrated that frequency judgments are equally accurate under incidental and intentional learning conditions, are not affected by practice, and are insensitive to subject variables such as age and depression (e.g., Hasher \& Chromiak, 1977; Hasher \& Zacks, 1979; Hintzman, Nozawa, \& Irmscher, 1982; Howell, 1973; Zacks et al., 1982), whereas free-recall performance is affected by all of the foregoing variables (Hasher \& Zacks, 1979; Zacks et al., 1982). Although some evidence suggests that frequency information is not encoded entirely automatically (Greene, 1984), the data nevertheless suggest that memory for this kind of information, which is impaired in frontal patients (Smith \& Milner, 1983), does not require a great deal of effortful processing.

Several studies concerned with memory for temporal order point to a similar conclusion. Hintzman and his colleagues found that subjects who are instructed only "to prepare for a memory test" perform with high levels of accuracy when they are unexpectedly required to remember the ordinal position of an item within a list (Hintzman \& Block, 1973; Hintzman, Block, \& Sumners, 1973), judge the spacing between two items (Hintzman \& Block, 1973; Hintzman, Sumners, \& Block, 1975), or state in which of two lists an item appeared (Hintzman et al., 1973). Similar findings have been reported in twochoice recency judgment paradigms: Guenther and Linton (1975) found above-chance levels of performance when subjects were given an unexpected recency test for pictures, and Tzeng and Cotton (1980) observed a similar phenomenon with words. Moreover, it has also been found that providing subjects with explicit instructions about a temporal memory test does not affect performance. Zimmerman and Underwood (1968) tested temporal memory by having subjects judge the ordinal posi- 
tions of a series of 12-word lists that had been presented and tested for recall sequentially. Position judgments of subjects who were informed about the temporal task were no more accurate than were those of subjects who were instructed that "memory" would be tested. Similarly, Toglia and Kimble (1976) found no differences between instructed and uninstructed subjects when they were asked to judge in which part of a list an item had occurred.

The foregoing studies demonstrate that subjects need not be informed of a temporal memory task in order to perform well on it. Note, however, that these studies used tasks that were "incidental" in a weak sense: the subjects were always given general instructions that memory would be tested. This fact raises a problem for any attempt to interpret the aforementioned data as suggesting that temporal information is encoded automatically: It is possible that high levels of performance on temporal tasks are attributable to strategic, effortful processes initiated by subjects to prepare for the anticipated "memory test." Indeed, recent theoretical accounts of temporal memory imply that rehearsal processes during list presentation may underlie performance on temporal tasks (Hintzman et al., 1975; Tzeng \& Cotton, 1980). With respect to impaired temporal memory in frontal patients, it could be argued that poor performance is attributable to a general failure of strategic processing, and not to a failure of an automatic process concerned specifically with temporal information.

To argue that temporal information can be encoded automatically, it would be important to demonstrate high levels of performance on tasks that were "incidental" in a strong sense, with subjects not being informed of any kind of memory test. There is as yet little relevant evidence, but the existing data support an automaticity view. In a study reported by Fritzen (1977), subjects made semantic judgments about words on two different lists. For some of the subjects, no mention was made of a memory test; other subjects were informed that "memory" would be tested. Fritzen found that list discrimination performance in incidental conditions was as accurate as, or more accurate than, performance in the informed condition. Proctor and Ambler (1975) compared accuracy of spacing judgments under two instructional conditions: In one condition, subjects were instructed to rehearse only the current list item; in the other condition, no restrictions were placed on type of rehearsal. If accuracy of temporal judgments depends upon effortful processes of interitem organization, one would expect higher performance in the free rehearsal condition than in the restricted rehearsal condition. However, Proctor and Ambler found that accuracy of spacing judgments was generally similar in the two conditions; when there was a difference, it favored the restricted rehearsal condition.

In an attempt to provide further pertinent data, I conducted an experiment that compared the accuracy of recency judgments in incidental and intentional conditions. Subjects in the incidental condition were asked to rate the pleasantness of a series of words; subjects in the intentional condition performed the same rating task and, in addition, were informed that a recency judgment task would be given after list presentation. In both conditions, half of the test pairs were composed of unrelated words (e.g., HUSBAND-ROCKET) and half were composed of related words (e.g., TABLE-CHAIR). The subjects were asked to indicate which of the two items had occurred more recently in the list. In conformity with the results of previous research (Hintzman et al., 1975; Tzeng \& Cotton, 1980), temporal judgments were more accurate for related test pairs than for unrelated test pairs (Table 1). More importantly, however, it was found that accuracy of recency judgments exceeded the chance level in each of the four main experimental conditions, and did not differ in the incidental and intentional groups (Table 1).

Although one must always be wary about accepting the null hypothesis, the foregoing studies suggest that performance on a variety of temporal judgment tasks is insensitive to instructional manipulations, and that subjects perform equally accurately whether or not they know that any kind of retention test will be administered. By contrast, recall and recognition performance are affected by the appropriateness of encoding instructions (e.g., Tversky, 1977). Evidence also exists to show that spatial information may be encoded automatically (e.g., Mandler, Seegmiller, \& Day, 1977; Rothkopf, 1971; Zechmeister, McKillip, Pasko, \& Bespalec, 1975). However, the relevant studies have been concerned with memory for the spatial positions of objects and items in complex arrays, and not with global information concerning where an episode occurred, which is the aspect of "spatial memory" of concern here.

Taken together, the studies discussed in this section indicate that memory for some kinds of spatiotemporal information does not depend upon effortful, strategic processing. These studies support the idea that disproportionate deficits of spatiotemporal memory observed after frontal lobe damage need not be attributable to general failures of strategic or effortful processing, but are produced by the failure of a specific mechanism that functions automatically in the absence of frontal pathology. Consistent with this idea, it is important to emphasize that, as noted earlier, patients with restricted frontal lesions can be unimpaired on free-recall tasks. Free recall is typically viewed as the prime example of an effort-demanding, strategically sensitive memory task (Hasher \& Zacks, 1979). If frontal patients suffered from a generalized

Table 1

Proportions of Correct Recency Judgments for Related and Unrelated Word Pairs in Intentional and Incidental Study Conditions

\begin{tabular}{cccc}
\hline \multirow{2}{*}{$\begin{array}{c}\text { Study } \\
\text { Condition }\end{array}$} & \multicolumn{3}{c}{ Type of Word Pair } \\
\cline { 2 - 4 } & Related & Unrelated & Mean \\
\hline Intentional & .87 & .74 & .81 \\
Incidental & .89 & .73 & .81 \\
Mean & .88 & .74 & \\
\hline
\end{tabular}


deficit of effortful processing, they should perform quite poorly on free-recall tasks.

\section{Summary and Concluding Comments}

Let us now summarize the evidence considered in the preceding three sections and relate it to the previously reviewed data on amnesic patients and to the ideas discussed regarding interpretation of frontal influences in organic amnesia. Three key points have been made: (1) Patients with restricted frontal lesions exhibit deficits in remembering certain kinds of contextual or spatiotemporal information; (2) similar deficits have been observed in studies of nonhuman primates with frontal lesions, which have shown that memory for spatiotemporal information is handled by specific and restricted areas of the prefrontal cortex; and (3) encoding of spatiotemporal information in humans can be accomplished relatively automatically.

Taken together, these observations indicate that frontal lobe influences on organic amnesia need not and should not be viewed as nonspecific effects that result from general failures of motivation or strategic processing. The data, instead, suggest that frontal lobe pathology can be associated with a failure in a highly specific form of memory function. Accordingly, it is justifiable empirically and useful heuristically to propose that (1) amnesic patients with additional frontal-related memory problems represent a type of amnesic syndrome that differs qualitatively from that exhibited by patients who are entirely free of frontal signs but is equally central to our understanding of memory disorders; and (2) patients exhibiting this form of amnesia may provide insights into the nature of normal memory function that are different from those provided by the study of so-called "pure" amnesic patients.

These conclusions are in some respects similar to, and in other respects different from, ideas put forward by others regarding the interpretation of frontal lobe influences in amnesic patients. A number of students of amnesia have argued that it is necessary to distinguish between memory deficits that are attributable to damage in medial temporal and diencephalic structures and those that are attributable to damage in frontal regions (Mayes \& Meudell, 1983; Mayes et al., 1985; Moscovitch, 1982; Squire, 1982a, 1982b, 1987; Squire \& Cohen, 1984). Memory deficits associated with damage to medial temporal and diencephalic structures are held to be responsible for the basic or core amnesic deficit, whereas damage to frontal regions is held to produce cognitive impairments that are incidental to, and superimposed on, the core amnesia (e.g., Mayes \& Meudell, 1983; Squire, 1982a, 1982b; Squire \& Cohen, 1984).

The major point of agreement between the present view and the foregoing ideas is that it is crucial to distinguish between memory deficits in amnesic patients that are attributable to frontal damage and those that are not. Frontal-related memory deficits are specific to certain kinds of spatiotemporal information and appear to be tied closely to specific processing functions (i.e., temporal and sequential organization), whereas memory deficits attributable to medial temporal and diencephalic damage are global and include many different types of information. This point has been articulated clearly by Squire (1987), and is entirely consistent with the ideas put forward here. The major difference betwen the present view and the position taken by Squire (1982a, 1982b; Squire \& Cohen, 1984) and Mayes and Meudell (1983) is perhaps less one of substance than one of emphasis. If frontalrelated deficits in amnesic patients are viewed as incidental problems that are separate from a hypothetical "core" amnesic syndrome, it follows that theoretical attention should be focused on the core syndrome; the so-called incidental deficits are of interest only insofar as they need to be identified and then excluded from the analysis of amnesia. By following such a strategy, one could easily minimize or overlook the theoretical significance of frontal-related memory deficits that have been observed in amnesic patients. It is also not entirely clear how to determine what constitutes the "core" amnesic syndrome. Although one could argue that only deficits associated specifically with damage to the medial temporal and diencephalic regions should be included in the core syndrome, there is a good deal of circularity in such an approach: It presupposes understanding of the neural substrate of memory, whatever the outcome of empirical studies. Moreover, some evidence suggests that amnesic patients with medial temporal and diencephalic damage differ with respect to certain aspects of memory performance (e.g., Huppert \& Piercy, 1982; Squire, 1982b; but see Weiskrantz, 1985). If medial temporal and diencephalic lesions produce different patterns of deficit, the validity of the notion of a single core syndrome is uncertain, and the usefulness of drawing a sharp distinction between "core" and "incidental" deficits is thus further called into question. On the other hand, if the type of amnesic syndrome exhibited by patients with frontal-related memory deficits is viewed as being different from that exhibited by patients without frontal-related deficits, as suggested here, it follows that theoretical analyses should focus on understanding both types of amnesia and delineating further the relationship between them.

I have argued that amnesic patients with frontal signs exhibit disproportionately impaired memory for spatiotemporal context, whereas patients who are entirely free of frontal signs do not show disproportionate spatiotemporal deficits. Thus, it may be useful to classify different amnesic patients according to the degree of impairment found in their retrieval of spatiotemporal information relative to item information. However, I am not proposing that patients should be classified into two discrete, mutually exclusive categories on either psychological or neuroanatomical grounds. The magnitude of spatiotemporal deficits is most certain to vary in a continuous manner-depending on the exact nature and extent of frontal involvement-and hence should not be treated as an all-or-none phenomenon. It is likely to be 
more useful to attempt to delineate a gradient of the severity of spatiotemporal memory defects, relative to item retention defects, and to characterize amnesic patients according to where they fall on such a gradient. By acknowledging that amnesic patients vary in the extent to which spatiotemporal memory is impaired relative to item memory, it may be possible to settle disagreements in the literature concerning the nature of the "fundamental deficit" in amnesia. Several researchers have argued that amnesic patients have special deficits in remembering the spatiotemporal contexts in which items and events occur (e.g., Kinsbourne \& Wood, 1975; Rozin, 1976; Schacter \& Tulving, 1982a, 1982b; Stern, 1981; Tulving, 1983) and hence amnesic patients are characterized by a selective deficit of episodic memory (Tulving, 1972). By contrast, others have argued that amnesics' spatiotemporal memory deficits are no more severe than the deficits they exhibit in remembering any kind of declarative information, including items, facts, and associations (e.g., Mayes \& Meudell, 1983; Squire \& Cohen, 1984; Zola-Morgan, Cohen, \& Squire, 1983). In light of the evidence discussed here, it can be seen that neither of these positions applies uniformly to all amnesic patients. Rather, each position may be correct when applied to a particular subtype of patient: amnesics who are entirely or largely free of frontal damage may be equally impaired on all forms of declarative information, whereas those with significant frontal lobe dysfunction are likely to have special difficulties with episodic remembering.

Similar considerations apply to the question of whether phenomena observed in amnesic patients can aid in the understanding of normal memory. A number of neuropsychologists and cognitive psychologists have recently argued that the selective retention deficits observed in amnesia may have important implications for the understanding of normal memory function (e.g., Baddeley, 1982; Kinsbourne \& Wood, 1975; Moscovitch, 1982; Schacter, in press; Schacter \& Tulving, 1982a, 1982b; Squire, 1982b). It has been less widely recognized, however, that different types of amnesic patients may provide insight into different types of mnemonic function. For example, a "pure" bitemporal amnesic, such as patient H.M., who is free of frontal pathology, may provide useful information concerning the general breakdown of retentionconsolidation processes that are necessary for remembering many different types of information. By contrast, the main theoretical attraction of amnesics with frontal pathology (and of frontal patients who are not amnesic) is that they may facilitate understanding of specific psychological functions that underlie memory for spatiotemporal information. Evidence from studies of normal subjects indicates that memory for temporal order information can be dissociated experimentally from item recall and recognition (Bjork \& Healy, 1974; Healy, 1982; Murdock, 1976). Although theoretical understanding of the basis of memory for temporal order is still uncertain (e.g., Healy, 1982; Tzeng \& Cotton, 1980), there is reason to believe that different mechanisms may underlie memory for item and temporal order information (Murdock, 1982). Studies of frontal patients may help to elucidate these mechanisms.

Finally, it seems appropriate to consider briefly the nature of the impaired mechanism that is responsible for the disproportionate spatiotemporal deficits associated with frontal dysfunction. To state that such deficits are attributable to failures of a specific, automatic mechanism that depends upon the integrity of the prefrontal cortex may be a useful beginning step, but it does not provide much insight into the nature of the deficient mechanism or process. One promising idea that has been suggested by a number of investigators is that frontal regions play a major role in the segmentation and organization of ongoing experience into distinctive units that are discriminable from one another (Fuster, 1980; Milner, 1982; Pribram \& Tubbs, 1967; Tubbs, 1969)-a process that I will refer to as contextual chunking. If an organism were unable to organize experience into temporally distinctive chunks, then it would prove extremely difficult for it to discriminate among recent experiences with respect to features such as time and space. It would also be difficult for such an organism to organize recent events sequentially, because the component events would not be clearly differentiated. Thus, the organism might remember isolated contents of recent experiences, but fail to recollect the spatial and temporal features that identify each experience as a separate entity. In many respects, this is exactly what is observed after restricted damage to prefrontal cortex in man and monkey: Retention of information about the content of recently experienced events is relatively undisturbed, whereas retention of spatiotemporal information is severely compromised.

The general idea that temporal deficits associated with frontal lobe dysfunction in brain-damaged monkeys and humans can be attributed to a failure of contextual chunking or some similar process has been proposed by neuropsychological investigators. Evidence for the importance of a contextual chunking process, however, has also surfaced in the psychological study of temporal memory in normal subjects. Consider, for example, an experiment reported by Poynter (1983). Poynter's subjects studied lists of common words. A number of highly distinctive items-the names of U.S. presidents-were included in the lists. In one condition, the distinctive names were interspersed at regular intervals through the list. Poynter reasoned that the distinctive names would help subjects to segment or chunk the list into successive temporal components. In other conditions, the presidents' names all occurred at the beginning or at the end of the list. Thus, although the same no minal stimuli appeared in all conditions, they served to segment the study duration in one condition but not in the others. Poynter found that recall and recognition performance did not differ in the segmented and unsegmented conditions. However, Poynter also asked subjects to make judgments concerning the temporal duration of the study interval. He observed a large effect of internal segmentation on remembered duration: Subjects who had the segmented list judged the temporal 
duration of list presentation as being longer than did the subjects who had studied the unsegmented list. These data suggest that contextual chunking is related to temporal memory, but not to item memory (see Block, 1982, for a similar conclusion), and in that sense complement the data concerning patients with frontal dysfunction.

The notion that the prefrontal cortex is involved in the contextual chunking process requires further elaboration, specification, and empirical support. It is not yet certain how this process is related to the various other impairments that can occur as a consequence of frontal lobe pathology, nor is its precise neuroanatomical substrate understood. But what does seem clear is that a process such as contextual chunking is intimately involved with the highest forms of mnemonic function. Studies of amnesic patients with frontal lobe pathology could provide important insights into the nature of this process. Although we must be careful to distinguish between the kinds of inferences that can be made about normal memory function when amnesic patients show signs of frontal pathology and when they do not, it is possible that the study of patients with frontal lobe pathology will help to dissect the components of remembering in a way that study of socalled "pure" amnesics cannot. By acknowledging that memory deficits associated with frontal lobe dysfunction can provide useful clues concerning an important form of mnemonic function, it may be possible to gain a fuller understanding of memory from a study of its pathology.

\section{REFERENCES}

Baddeley, A. D. (1982). Amnesia: A minimal model and an interpretation. In L. S. Cermak (Ed.), Human memory and amnesia. Hillsdale, NJ: Erlbaum.

BADDELEY, A. D., \& Wilson, B. (1986). Amnesia, autobiographical memory, and confabulation. In D. C. Rubin (Ed.), Autobiographical memory (pp. 225-252). New York: Cambridge University Press.

BaUER, R. H., Fuster, J. M. (1976). Delayed-matching and delayedresponse deficit from cooling dorsolateral prefrontal cortex in monkeys. Journal of Comparative \& Physiological Psychology, 90, 293-302.

Bauer, R. H., \& Fuster, J. M. (1978). The effect of ambient illumination on delayed-matching and delayed-response deficits from cooling dorsolateral prefrontal cortex. Behavioral Biology, 22, 60-66.

Benton, A. L. (1968). Differential behavioral effects in frontal lobe disease. Neuropsychologia, 6, 53-60.

BJork, E. L., \& HeAly, A. (1974). Short-term order and item retention. Journal of Verbal Learning \& Verbal Behavior, 13, 80-97.

Buock, R. A. (1982). Temporal judgments and contextual change. Journal of Experimental Psychology: Learning, Memory, \& Cognition, 8, 530-544.

Butters, N., Pandya, D., Stein, D., \& Rosen, J. (1972). A search for the spatial engram within the frontal lobes of monkeys. Acta Neurobiologiae Experimentalis, 32, 305-329.

ButTERs, N., CERMAK, L. S. (1980). Alcoholic Korsakoffs syndrome. New York: Academic Press.

Butters, N., \& Muotis, P. (1985). Amnesic disorders. In K. M. Heilman \& E. Valenstein (Eds.), Clinical neuropsychology. New York: Oxford University Press.

Cermak, L. S. (1976). The encoding capacity of a patient with amnesia due to encephalitis. Neuropsychologia, 14, 311-322.

Cermak, L. S. (Ed.). (1982). Human memory and amnesia. Hillsdale, NJ: Erlbaum.

Cermak, L. S., Butters, N., \& Morennes, J. (1974). Some analyses of the verbal encoding deficit in alcoholic Korsakoff patients. Brain \& Language, 1, 141-150.

Chorover, S. L., \& COLE, M. (1966). Delayed alternation performance in patients with cerebral lesions. Neuropsychologia, 4, 1-7.

ClaparÉde, E. (1951). Recognition and 'me-ness.' In D. Rapaport (Ed. \& Trans.), Organization and pathology of thought. New York: Columbia University Press. (Reprinted from Archives de Psychologie, 1911, 11, 79-90)

Damasio, A. R. (1979). The frontal lobes. In K. M. Heilman \& E. Valenstein (Eds.), Clinical neuropsychology (pp. 360-412). Oxford: Oxford University Press.

Damasio, A. R., Graff-Radford, N. R., Eslinger, P. J., Damasio, H., \& KASSELL, N. (1985). Amnesia following basal forebrain lesions. Archives of Neurology, 42, 263-271.

Damasio, A. R., V VAN Hoesen, G. W. (1983). Emotional disturbances associated with focal lesions of the frontal lobe. In K. Heilman \& P. Satz (Eds.), The neurophysiology of human emotion: Recent advances. New York: Guilford Press.

DELla RocchetTA, A. I. (1986). Classification and recall of pictures after unilateral frontal or temporal lobectomy. Cortex, 22, 189-211.

DiAMOND, A. (1985). Development of the ability to use recall to guide action, as indicated by infants' performance on $\mathbf{A} \overline{\mathbf{B}}$. Child Development, 56, 868-883.

Diamond, A., Goldman-Rakic, P. (1983). Comparison of performance on a Piagetian object permanence task in human infants and rhesus monkeys: Evidence for involvement of prefrontal cortex. Society for Neuroscience Abstracts, 9, 641.

Drewe, E. A. (1974). The effect of type and area of brain lesion on Wisconsin Card Sorting Test performance. Cortex, 10, 159-170.

DREWE, E. A. (1975). An experimental investigation of Luria's theory on the effects of frontal lobe lesions in man. Neuropsychologia, 13, $421-429$.

EsLINGER, P. J., \& DAMAsio, A. R. (1985). Severe disturbance of higher cognition after bilateral frontal lobe ablation: Patient EVR. Neurology, 35, 1731-1741.

Evans, F. J., \& ThorN, W. A. F. (1966). Two types of posthypnotic amnesia: Recall amnesia and source amnesia. International Journal of Clinical \& Experimental Hypnosis, 14, 162-179.

Freedman, M., \& Cermak, L. S. (1986). Semantic encoding deficits in frontal lobe disease and amnesia. Brain \& Cognition, 5, 108-114.

Fritzen, J. D. (1977). Orienting tasks as sources of contextual information in list discrimination. Journal of Experimental Psychology: Human Leaming \& Memory, 3, 119-128.

FUSTER, J. M. (1980). The prefrontal cortex: Anatomy, physiology, and neuropsychology of the frontal lobe. New York: Raven Press.

FusTER, J. M. (1985). The prefrontal cortex, mediator of cross-temporal contingencies. Human Neurobiology, 4, 169-179.

FUSTER, J. M., \& BAUER, R. H. (1974). Visual short-term memory deficit from hypothermia of frontal cortex. Brain Research, 81, 393-400.

GheNT, L., Mishind, M., \& Teuber, H.-L. (1962). Short term memory after frontal lobe injury in man. Journal of Comparative \& Physiological Psychology, 55, 705-709.

Guick, S. D., GoldFarb, T. L., \& JARVIK, M. E. (1969). Recovery of delayed matching performance following lateral frontal lesions in monkeys. Communications in Behavioral Biology, 3, 299-303.

Goldman, P. S., Rosvold, H. E. (1970). Localization of function within the dorsolateral prefrontal cortex of the rhesus monkey. Experimental Neurology, 27, 291-304.

Goldman, P. S., Rosvold, H. E., Vest, B., \& Galkin, T. W. (1971). Analysis of the delayed-alternation deficit produced by dorsolateral prefrontal lesions in the rhesus monkey. Journal of Comparative \& Physiological Psychology, 77, 212-220.

Goldman-RAKic, P. S. (1984). The frontal lobes: Uncharted provinces of the brain. Trends in Neuroscience, 7, 425-429.

GreENE, R. L. (1984). Incidental learning of event frequency. Memory \& Cognition, 12, 90-95.

Guenther, R. K., Linton, M. (1975). Mechanisms of temporal coding. Joumal of Experimental Psychology: Human Leaming \& Memory, 104, 182-187.

Hasher, L., Chromak, W. (1977). The processing of frequency 
information: An automatic mechanism? Journal of Verbal Learning \& Verbal Behavior, 16, 173-184.

HASHER, L., \& ZACKs, R. T. (1979). Automatic and effortful processes in memory. Journal of Experimental Psychology: General, 108, 356-388.

Healy, A. F. (1982). Short-term memory for order information. In G. H. Bower (Ed.), The psychology of learning and motivation (Vol. 16, pp. 191-238). New York: Academic Press.

HÉCAEN, H., \& AlBERT, M. L. (1975). Disorders of mental functioning related to frontal lobe pathology. In D. F. Benson \& D. Blumer (Eds.), Psychiatric aspects of neurologic disease (Vol. 1, pp. 137149). New York: Grune \& Stratton.

Hintzman, D. L., \& Block, R. A. (1973). Memory for the spacing of repetitions. Journal of Experimental Psychology, 99, 70-74.

Hintzman, D. L., Block, R. A., \& Sumners, J. J. (1973). Modality tags and memory for repetitions: Locus of the spacing effect. Journal of Verbal Learning \& Verbal Behavior, 12, 229-239.

Hintzman, D. L., Nozawa, G., \& Irmscher, M. (1982). Frequency as a nonpropositional attribute of memory. Journal of Verbal Learning \& Verbal Behavior, 21, 127-141.

Hintzman, D. L., Sumners, J. J., \& Block, R. A. (1975). Spacing judgments as an index of study-phase retrieval. Joumal of Experimental Psychology: Human Learning \& Memory, 1, 430-434.

HiRsT, W. (1982). The amnesic syndrome: Descriptions and explanations. Psychological Bulletin, 91, 435-460.

HiRsT, W., \& VolPE, B. T. (1982). Temporal order judgments with amnesia. Brain \& Cognition, 1, 294-306.

Howell, W. C. (1973). Storage of events and event frequencies: A comparison of two paradigms in memory. Journal of Experimental Psychology, 98, 260-263.

Huppert, F. A., \& Piercy, M. (1976). Recognition memory in amnesic patients: Effect of temporal context and familiarity of material. Cortex, 12, 3-20.

Huppert, F. A., \& Piercy, M. (1978). The role of trace strength in recency and frequency judgements by amnesic and control subjects. Quarterly Journal of Experimental Psychology, 30, 347-354.

HuPPERT, F. A., \& PIERCY, M. (1982). In search of the functional locus of amnesic syndromes. In L. S. Cermak (Ed.), Human memory and amnesia (pp. 123-137). Hillsdale, NJ: Erlbaum.

INGVAR, D. H. (1983). Serial aspects of language and speech related to prefrontal cortical activity: A selective review. Human Neurobiology, 2, 177-190.

INGVAR, D. H. (1985). "Memory of the future": An essay on the temporal organization of conscious awareness. Human Neurobiology, 4, 127-136.

IVERSEN, S. D. (1983). Brain lesions and memory in animals: A reappraisal. In J. A. Deutsch (Ed.), The physiological basis of memory (pp. 139-198). New York: Academic Press.

JACOBSEN, C. F. (1935). Functions of the frontal association area in primates. Archives of Neurology \& Psychiatry, 33, 558-569.

Jetter, W., Poser, U., Freeman, R. B., JR., \& Markowitsch, H. J. (1986). A verbal long term memory deficit in frontal lobe damaged patients. Cortex, 22, 229-242.

Jones-Gotman, M., \& Milner, B. (1977). Design fluency: The invention of nonsense drawings after focal cortical lesions. Neuropsychologia, 15, 653-674.

Kinsbourne, M., \& Winocur, G. (1980). Response competition and interference effects in paired-associate learning by Korsakoff amnesics. Neuropsychologia, 18, 541-548.

KinsbouRNE, M., \& WoOD, F. (1975). Short-term memory and the amnesic syndrome. In D. D. Deutsch \& J. A. Deutsch (Eds.), Shortterm memory. New York: Academic Press.

KoLB, B. (1984). Functions of the frontal cortex of the rat: A comparative review. Brain Research Review, 8, 65-98.

KoLB, B., \& WHISHAW, I. Q. (1985). Fundamentals of human neuropsychology. San Francisco: W. H. Freeman.

KovNer, R., \& STAmm, J. S. (1972). Disruption of short-term visual memory by electrical stimulation of inferotemporal cortex. Journal of Comparative \& Physiological Psychology, 81, 163-172.

Lewinsohn, P. M., Zieler, J. L., Libet, J., Eyeberg, S., \& NielsoN, G. (1972). Short-term memory: A comparison between frontal and nonfrontal right- and left-hemisphere brain-damaged patients. Journal of Comparative \& Physiological Psychology, 81, 248-255.

LuRIA, A. R. (1969). Frontal lobe syndromes. In P. J. Vinken \& G. W. Bruyn (Eds.), Handbook of clinical neurology (Vol. 2, pp. 725-757). Amsterdam: North Holland.

LURIA, A. R. (1971). Memory disturbances in local brain lesions. Neuropsychologia, 9, 267-375.

LURIA, A. R. (1973). The frontal lobes and the regulation of behavior. In K. H. Pribram \& A. R. Luria (Eds.), Psychophysiology of the frontal lobes (pp. 3-26). New York: Academic Press.

LURIA, A. R. (1976). The neuropsychology of memory. Washington, DC: V. H. Winston.

MACCuRDY, J. T. (1928). Common principles in psychology and physiology. Cambridge: The University Press.

MALMO, R. B. (1942). Interference factors in delayed response in monkeys after removal of the frontal lobes. Journal of Neurophysiology, 5, 295-308.

Mandler, J. M., Seegmiller, D., \& DAY, J. (1977). On the coding of spatial information. Memory \& Cognition, 5, 10-16.

MAYes, A. R., \& MEudell, P. R. (1981a). How similar is immediate memory in amnesic patients to delayed memory in normal subjects? A replication, extension, and reassessment of the amnesic cueing effect. Neuropsychologia, 19, 647-654.

Mayes, A., Meudell, P. R. (1981b). How similar is the effect of cueing in amnesics and in normal subjects following forgetting? Cortex, 17, 113-124.

Mayes, A., \& Meudell, P. R. (1983). Amnesia in humans and other animals. In A. Mayes (Ed.), Memory in animals and humans. Cambridge: Van Nostrand Reinhold.

Mayes, A. R., Meudell, P. R., \& Pickering, A. (1985). Is organic amnesia caused by a selective deficit in remembering contextual information. Cortex, 21, 167-202.

Mayes, A. R., Meúdell, P. R., \& Som, S. (1981). Further similarities between amnesic and normal attenuated memory: Effects with paired-associate learning and contextual shifts. Neuropsychologia, 19, 655-664.

Meudell, P. R., Mayes, A. R., Ostergaard, A., \& Pickering, A. (1985). Recency and frequency judgements in alcoholic amnesics and normal people with poor memory. Cortex, 21, 487-511.

Meyer, D. R., HaRlow, H. F., \& Settlage, P. H. (1951). A survey of delayed performance by normal and brain-damaged monkeys. Journal of Comparative \& Physiological Psychology, 44, 17-25.

Miller, M. H., \& ORBACH, J. (1972). Retention of spatial alternation following frontal lobe resections in stump-tailed macaques. Neuropsychologia, 10, 291-298.

MiLNER, B. (1963). Effects of different brain lesions on card sorting. Archives of Neurology, 9, 100-110.

MILNER, B. (1964). Some effects of frontal lobectomy in man. In J. M. Warren \& K. Akert (Eds.), The frontal granular cortex and behavior (pp. 313-334). New York: McGraw-Hill.

MiLNER, B. (1967). Brain mechanisms suggested by studies of temporal lobes. In C. H. Millikan \& F. L. Darley (Eds.), Brain mechanisms underlying speech and language (pp. 122-145). New York: Grune \& Stratton.

MILNER, B. (1971). Interhemispheric differences in the localization of psychological processes in man. British Medical Bulletin, 27, 272-277. MiLner, B. (1974). Hemispheric specialization: Scope and limits. In F. O. Schmitt \& F. G. Worden (Eds.), The neurosciences: Third study program (pp. 75-89). Cambridge: MIT Press.

MILNER, B. (1982). Some cognitive effects of frontal lobe lesions in man. In D. E. Broadbent \& L. Weiskrantz (Eds.), The neuropsychology of cognitive function (pp. 211-226). London: The Royal Society.

MiLner, B., KolB, B. (1985). Performance of complex arm movements and facial-movement sequences after cerebral commissurotomy. Neuropsychologia, 23, 791-799.

Milner, B., Petrides, M., \& Smith, M. L. (1985). Frontal lobes and the temporal organization of memory. Human Neurobiology, 4, 137-142.

Mishrin, M. (1964). Perseveration of central sets after frontal lesions in monkeys. In J. M. Warren \& K. Akert (Eds.), The frontal granular cortex and behavior (pp. 219-241). New York: McGraw-Hill. 
Mishkin, M., \& BacheValier, J. (1983). Object recognition impaired by ventromedial but not dorsolateral prefrontal cortical lesions in monkeys. Society for Neuroscience Abstracts, 9, 29.

Mishkin, M., \& ManNing, F. J. (1978). Non-spatial memory after selective prefrontal lesions in monkeys. Brain Research, 143, 313-323.

Mishion, M., \& Pribram, K. H. (1955). Analysis of the effects of frontal lesions in monkey: 1. Variations of delayed alternation. Journal of Comparative \& Physiological Psychology, 48, 492-495.

Mishkin, M., \& PRIBRAM, K. H. (1956). Analysis of the effects of frontal lesions in monkey: II. Variations of delayed response. Joumal of Comparative \& Physiological Psychology, 49, 36-40.

Mishkin, M., VEST, B., WaxLer, M., Rosvold, E. (1969). A reexamination of the effects of frontal lesions on object alternation. Neuropsychologia, 7, 357-363.

Moscovitch, M. (1982). Multiple dissociations of function in amnesia. In L. S. Cermak (Ed.), Human memory and amnesia (pp. 337370). Hillsdale, NJ: Erlbaum.

MuRDock, B. B., JR. (1976). Item and order information in short-term serial memory. Journal of Experimental Psychology: General, 105, 191-216.

Murdock, B. B., JR. (1982). A theory for the storage and retrieval of item and associative information. Psychological Review, 89, 609-626.

Nauta, W. J. H. (1971). The problem of the frontal lobe: A reinterpretation. Journal of Psychiatric Research, 8, 167-187.

Nauta, W. J. H. (1973). Connections of the frontal lobe with the limbic system. In L. V. Laitinen \& K. E. Livingston (Eds.), Surgical approaches in psychiatry (pp. 303-314). Baltimore: University Park Press.

Oscar-Berman, M. (1975). The effect of dorsolateral-frontal and ventrolateral-orbitofrontal lesions on spatial discrimination learning and delayed response in two modalities. Neuropsychologia, 13, 237-246.

OsCar-Berman, M. (1980). Neuropsychological consequences of longterm chronic alcoholism. American Scientist, 68, 410-419.

Passingham, R. E. (1975). Delayed matching after selective prefrontal lesions in monkeys (Macaca mulatta). Brain Research, 92, 89-102.

Passingham, R. E. (1985). Memory of monkeys (Macaca mulatta) with lesions in prefrontal cortex. Behavioral Neuroscience, 99, 3-21.

Petrides, M. (1985). Deficits on conditional associative-learning tasks after frontal- and temporal-lobe lesions in man. Neuropsychologia, 23, 601-614.

Petrides, M., \& Milner, B. (1982). Deficits on subject-ordered tasks after frontal and temporal lobe lesions in man. Neuropsychologia, 20, 249-262.

PIERCY, M. F. (1977). Experimental studies of the organic amnesic syndrome. In C. W. M. Whitty \& O. L. Zangwill (Eds.), Amnesia (2nd ed., pp. 1-51). London: Butterworths.

Poynter, W. D. (1983). Duration judgment and the segmentation of experience. Memory \& Cognition, 11, 77-82.

Pribram, K. H., Ahumada, A., Hartog, J., \& Roos, I. (1964). A progress report on the neurological processes disturbed by frontal lesions in primates. In J. M. Warren \& K. Akert (Eds.), The frontal granular cortex and behavior (pp. 28-55). New York: McGraw-Hill.

Pribram, K. H., \& Tubbs, W. E. (1967). Short term memory, parsing and the primate frontal cortex. Science, 156, 1765-1767.

Proctor, R. W., \& Ambler, B. A. (1975). Effects of rehearsal strategy on memory for spacing and frequency. Journal of Experimental Psychology: Human Learning \& Memory, 1, 640-647.

RoTHKOPF, E. Z. (1971). Incidental memory for location of information in test. Journal of Verbal Learning \& Verbal Behavior, 10, 608-613.

Rozin, P. (1976). The psychobiological approach to human memory. In M. R. Rosenzweig \& E. L. Bennett (Eds.), Neural mechanisms of learning and memory. Cambridge, MA: MTT Press.

SANDSON, J., \& ALBERT, M. L. (1984). Varieties of perseveration. Neuropsychologia, 22, 715-732.

SCHACTER, D. L. (in press). Implicit memory: History and current status. Journal of Experimental Psychology: Learning, Memory, \& Cognition.
Schacter, D. L., Harbluk, J. L., \& Mclachlan, D. R. (1984). Retrieval without recollection: An experimental analysis of source amnesia. Journal of Verbal Learning \& Verbal Behavior, 23, 593-611. SChacter, D. L., Moscovitch, M., Tulving, E., Mclachlan, D. R., \& Freedman, M. (1986). Mnemonic precedence in amnesic patients: An analogue of the $\mathrm{AB}$ error in infants? Child Development, 57, 816-823.

SCHACTER, D. L., Tulving, E. (1982a). Amnesia and memory research. In L. S. Cermak (Ed.), Human memory and amnesia (pp. 132). Hillsdale, NJ: Erlbaum.

Schacter, D. L., Tulving, E. (1982b). Memory, amnesia, and the episodic/semantic distinction. In R. L. Isaacson \& N. E. Spear (Eds.), The expression of knowledge (pp. 33-65). New York: Plenum Press.

Scoville, W. B., \& MiLNER, B. (1957). Loss of recent memory after bilateral hippocampal lesions. Journal of Neurology, Neurosurgery, \& Psychiatry, 20, 11-21.

Shallice, T. (1982). Specific impairments of planning. In D. E. Broadbent \& L. Weiskrantz (Eds.), The neuropsychology of cognitive function (pp. 199-209). London: The Royal Society.

Smith, M. L., \& MiLNER, B. (1983). Effects of focal brain lesions on sensitivity to frequency of occurrence. Society for Neuroscience $A b$ stracts, 9, Part I, 30.

SQuire, L. R. (1982a). Comparisons between forms of amnesia: Some deficits are unique to Korsakoff's syndrome. Journal of Experimental Psychology: Learning, Memory, \& Cognition, 8, 560-571.

Souire, L. R. (1982b). The neuropsychology of human memory. Annual review of Neuroscience, 5, 241-273.

SQuIRE, L. R. (1986). Mechanisms of memory. Science, 232, 1612-1619.

SQUIRE, L. R. (1987). Memory and brain. New York: Oxford University Press.

Squire, L. R., \& Cohen, N. J. (1984). Human memory and amnesia. In J. McGaugh, G. Lynch, \& N. Weinberger (Eds.), Proceedings of the Conference on the Neurobiology of Learning and Memory. New York: Guilford Press.

STAMm, J. (1969). Electrical stimulation of monkeys' prefrontal cortex during delayed-response performance. Journal of Comparative \& Physiological Psychology, 67, 535-546.

Stamm, J. S., \& Rosen, S. C. (1973). The locus and crucial time of implication of prefrontal cortex in the delayed response task. In K. Pribram \& A. R. Luria (Eds.), Psychophysiology of the frontal lobes. New York: Academic Press.

STERN, L. D. (1981). A review of theories of human amnesia. Memory \& Cognition, 9, 247-262.

Stuss, D. T., \& Benson, D. F. (1984). Neuropsychological studies of the frontal lobes. Psychological Bulletin, 95, 3-28.

STuss, D. T., \& BENSON, D. F. (1986). The frontal lobes. New York: Raven Press.

Stuss, D. T., Kaplan, E. F., Benson, D. F., Weir, W. S., Chiuld, S., SARAzin, F. F. (1982). Evidence for the involvement of orbitofrontal cortex in memory functions: An interference effect. Journal of Comparative \& Physiological Psychology, 96, 913-925.

Teuber, H.-L. (1964). The riddle of the frontal lobe in man. In J. M. Warren \& K. Akert (Eds.), The frontal granular cortex and behavior. New York: McGraw-Hill.

Teuber, H.-L., \& Weinstein, S. (1954). Performance on a formboardtask after penetrating brain injury. Joumal of Psychology, 38, 177-190.

TOGLIA, M. P., KIMBLE, G. A. (1976). Recall and use of serial position information. Journal of Experimental Psychology: Human Learning \& Memory, 2, 431-445.

Treichler, F. R., Hamilton, D. M., \& Halay, M. A. (1971). The influence of delay interval on severity of the spatial alternation deficit in frontal monkeys. Cortex, 7, 143-151.

TubBs, W. E. (1969). Primate frontal lesions and the temporal structure of behavior. Behavioral Science, 14, 347-356.

Tulving, E. (1972). Episodic and semantic memory. In E. Tulving \& W. Donaldson (Eds.), Organization of memory. New York: Academic Press.

Tulving, E. (1983). Elements of episodic memory. Oxford: Clarendon Press. 
Tversky, A. (1977). Features of similarity. Psychological Review, 84, 327-352.

Tzeng, O. J. L., \& CotTon, B. (1980). A study-phase retrieval model of temporal coding. Journal of Experimental Psychology: Human Learning \& Memory, 6, 705-716.

UNDERWOOD, B. J. (1977). Temporal codes for memories: Issues and problems. Hillsdale, NJ: Erlbaum.

W ALSH, K. W. (1978). Neuropsychology: A clinical approach. Edinburgh: Churchill Livingstone.

WARRINGTON, E. K., \& WeIskrantz, L. (1974). The effect of prior learning on subsequent retention in amnesic patients. Neuropsychologia, 12, 419-428.

WarRington, E. K., \& Weiskrantz, L. (1978). Further analysis of the prior learning effect in amnesic patients. Neuropsychologia, 16, 169-176.

Weiskrantz, L. (1985). On issues and theories of the human amnesic syndrome. In N. M. Weinberger, J. L. McGaugh, \& G. Lynch (Eds.), Memory systems of the brain (pp. 380-415). New York: Guilford Press.

WhitTY, C. W. M., \& ZANGWILl, O. L. (EDs.). (1977). Amnesia. London: Butterworths.

WiCKens, D. D. (1970). Encoding categories of words: An empirical approach to meaning. Psychological Review, 77, 1-15.

Witliams, M., \& ZANGWiLl, O. L. (1950). Disorders of temporal judgment in amnesic states. Journal of Mental Science, 94, 484-493.

WINOCUR, G. (1982). The amnesic syndrome: A deficit in cue utilization. In L. S. Cermak (Ed.), Human memory and amnesia (pp. 139166). Hillsdale, NJ: Erlbaum.
Winocur, G., \& Kinsbourne, M. (1978). Contextual cueing as an aid to Korsakoff amnesics. Neuropsychologia, 16, 671-682.

Winocur, G., KinsBourne, M., \& Moscovitch, M. (1981). The effect of cuing on release from proactive interference in Korsakoff amnesic patients. Journal of Experimental Psychology: Human Learning \& Memory, 7, 56-65.

WiNOCUR, G., \& WeISkRANTZ, L. (1976). An investigation of pairedassociate learning in amnesic patients. Neuropsychologia, 14, 97-110.

ZaCks, R. T., HASher, L., \& SANFT, H. (1982). Automatic encoding of event frequency: Further findings. Journal of Experimental Psychology: Learning, Memory, \& Cognition, 8, 106-116.

ZATORRE, R. J., \& MCENTER, W. J. (1983). Semantic encoding deficits in a case of traumatic amnesia. Brain \& Cognition, 2, 331-345.

Zechmeister, E. B., McKillip, J., Pasko, S., \& Bespalec, D. (1975). Visual memory for place on the page. Journal of General Psychology, 92, 43-52.

Zimmerman, J., \& UNDERWoOd, B. J. (1968). Ordinal position knowledge within and across lists as a function of instructions in freerecall learning. Journal of General Psychology, 79,1 301-307.

Zola-Morgan, S., Cohen, N. J., \& SuIRE, L. R. (1983). Recall of remote-episodic memory in amnesia. Neuropsychologia, 21, 487-500.

ZuBIN, J. (1948). Memory functioning in patients treated with electric shock therapy. Journal of Personality, 17, 33-41.

(Manuscript received June 27, 1986;

revision accepted for publication December 28, 1986.) 